\title{
E-SPORTS - OS JOGOS NO ÂMBITO DA COMUNICAÇÃO
}

\author{
Rayra Soares Gracia ${ }^{1}$ \\ Gabriel Cardoso Brito ${ }^{2}$ \\ Matheus Vinicius Vilela Lemes ${ }^{3}$ \\ Maria Gizele Pereira ${ }^{4}$
}

Resumo: O presente trabalho pretende socializar provas de como os "games" podem ser utilizados como ferramentas de integração e comunicação. A partir dos anos 2000 os jogos eletrônicos começaram a ganhar uma grande visibilidade, inclusive como esporte e agora há uma vasta quantidade de jogos online, o qual é um tema de conhecimento e de interesse de muitos jovens e adolescentes, jogos estes que são um meio de comunicação, que possuem uma forma distinta de imersão e "feedback". O foco deste trabalho será mais especificamente nos E-sports (eletronic sport), termo utilizado para denominar as competições profissionais de jogos eletrônicos.

Palavras-chave: Games, Comunicação, E-sports, Linguagem, Tecnologia.

\footnotetext{
${ }^{1}$ EEI Prof. Nelson do Nascimento Monteiro, Brasil. E-mail: rayra.gracia@hotmail.com.

2 EEI Prof. Nelson do Nascimento Monteiro, Brasil. E-mail: artesilksjc@hotmail.com.

${ }^{3}$ EEI Prof. Nelson do Nascimento Monteiro, Brasil. E-mail: gabriel.brito33@etec.sp.gov.br.

${ }^{4}$ EEI Prof. Nelson do Nascimento Monteiro, Brasil. E-mail: pereira.gizele@gmail.com.
} 